\title{
Study on Carbonation Index Prediction of Steel Fiber Concrete
}

\author{
Duo $\mathrm{Wu}^{1 *}$ \\ ${ }^{1}$ Department of Civil Engineering, Nanchang Institute of Technology, Nanchang Jiangxi 330029, China
}

\begin{abstract}
The addition of short steel wire, polypropylene, basalt and other fibers can improve the durability index of concrete, such as compression resistance, cracking resistance and carbonization resistance, which has been widely recognized in the industry. For the durability of fiber concrete, most of the current researches are qualitative, and the quantitative value of various index needs to be further investigated. In view of this, linear fitting and polynomial fitting were introduced into the prediction of durability index of fiber concrete in the present paper. The results show that the fitting method proposed is feasible and accurate for the carbonation index of fiber concrete.
\end{abstract}

\section{Introduction}

In recent years, with the innovation of fiber material technology, engineering structure has been further developed. An increasing number of engineering applications show that the incorporation of various fibers in concrete can significantly improve various mechanical properties [1-2] and durability indexes [3] of the structure. Many scholars have conducted researches on the mechanical properties of various fiber reinforced concrete materials, such as compression, shear and bending resistance [4-6] and durability indexes, such as freezethaw resistance [7], carbonization [8] and salt erosion [9], and achieved certain regular results.

Carbonation damage can lead to deterioration of concrete's appearance and strength performance, thus affecting the long-term durability life of concrete, which is a typical form of concrete durability damage. Since the 1960 s, the relevant countries began to study concrete carbonation. According to the influencing factors of concrete carbonation, a variety of methods of simulating carbonation test and related theoretical models were put forward. Many studies have been conducted on the carbonation effect of ordinary concrete. However, there are relatively few researches on durability indicators such as the carbonization of concrete mixed with fibers such as steel and polypropylene, and further research is needed.

\section{Analysis of Carbonization Mechanism of Steel Fiber Concrete}

\subsection{Steel fiber impact analysis}

Steel fiber is a typical concrete additive fiber. In the concrete mixing process, the gradual incorporation of steel fiber can improve the cracking resistance of concrete, reduce the weight of the concrete, increase the bond, and greatly improve the performance of concrete. The type and shape of steel fiber are shown in Table 1.

Table 1 Type and shape of steel fiber

\begin{tabular}{ccccc}
\hline Type & $\begin{array}{c}\text { Cold-drawn } \\
\text { steel-plastic } \\
\text { cut-off type }\end{array}$ & $\begin{array}{c}\text { Sheet } \\
\text { shear type }\end{array}$ & $\begin{array}{c}\text { Ingot } \\
\text { milling } \\
\text { type }\end{array}$ & $\begin{array}{c}\text { Low-alloy } \\
\text { steel } \\
\text { melting } \\
\text { type }\end{array}$ \\
\hline Shape & End hook & $\begin{array}{c}\text { Flat/ } \\
\text { Deformed }\end{array}$ & Deformed & Large head \\
\hline
\end{tabular}

Compared with ordinary concrete structures, steel fiber concrete has obvious advantages. The amount of concrete with the same strength can generally be reduced by $30-50 \%$, the amount of steel bars can be saved, the arch bridge can be shortened, and the construction is relatively simple. It is a kind of advantaged fiber-added concrete material.

The standard tensile strength of steel fiber concrete is determined according to Equation (1):

$$
f_{c f}=f_{f}\left(1+a_{t} \lambda_{t}\right)
$$

Where $f_{f}$ is the tensile strength standard value of concrete, unit is Mpa.

$\lambda_{t}$ is the characteristic value of steel fiber content.

$a_{t}$ is the influence factor of steel fiber on the tensile strength of concrete, as shown in Table 2.

$$
\lambda_{t}=\rho_{\mathrm{f}} l_{t} / d_{t}
$$

Where $\rho_{\mathrm{f}}$ is the volume ratio of steel fiber.

$l_{t}$ is the equivalent length of steel fiber.

$d_{t}$ is the equivalent diameter of steel fiber.

The standard bending and tensile strength of steel fiber can be calculated according to Equation (3):

$$
f_{c k}=f_{k}\left(1+a_{\mathrm{k}} \lambda_{t}\right)
$$

Where $f_{k}$ is the standard value of concrete bending tensile strength, unit is Mpa

$a_{k}$ is the influence factor of steel fiber on the flexural 
tensile strength of concrete, as shown in Table 2.

Table 2 Corresponding strength and index influencing factors of steel fiber concrete

\begin{tabular}{|c|c|c|c|c|}
\hline Type & Shape & $\begin{array}{l}\text { CF strength } \\
\text { grade }\end{array}$ & $a_{t}$ & $a_{k}$ \\
\hline \multirow{2}{*}{$\begin{array}{l}\text { Cold-drawn } \\
\text { steel-plastic cut- } \\
\text { off type }\end{array}$} & \multirow{2}{*}{ End hook } & $20 \mathrm{MP} \sim 45 \mathrm{MP}$ & 0.76 & 1.13 \\
\hline & & $50 \mathrm{MP} \sim 80 \mathrm{MP}$ & 1.03 & 1.25 \\
\hline \multirow{4}{*}{ Sheet shear type } & \multirow{2}{*}{ Flat } & $20 \mathrm{MP} \sim 45 \mathrm{MP}$ & 0.42 & 0.68 \\
\hline & & $50 \mathrm{MP} \sim 80 \mathrm{MP}$ & 0.46 & 0.75 \\
\hline & \multirow{2}{*}{ deformed } & $20 \mathrm{MP} \sim 45 \mathrm{MP}$ & 0.55 & 0.79 \\
\hline & & $50 \mathrm{MP} \sim 80 \mathrm{MP}$ & 0.63 & 0.93 \\
\hline \multirow{2}{*}{$\begin{array}{l}\text { Ingot milling } \\
\text { type }\end{array}$} & \multirow{2}{*}{ Deformed } & $20 \mathrm{MP} \sim 45 \mathrm{MP}$ & 0.7 & 0.92 \\
\hline & & $50 \mathrm{MP} \sim 80 \mathrm{MP}$ & 0.84 & 1.1 \\
\hline \multirow{2}{*}{$\begin{array}{l}\text { Low-alloy steel } \\
\text { melting type }\end{array}$} & \multirow{2}{*}{ Large head } & $20 \mathrm{MP} \sim 45 \mathrm{MP}$ & 0.52 & 0.73 \\
\hline & & $50 \mathrm{MP} \sim 80 \mathrm{MP}$ & 0.62 & 0.91 \\
\hline
\end{tabular}

\subsection{Carbonization mechanism analysis}

The $\mathrm{CO}_{2}$ in the air reacts easily with the alkaline substances in the concrete in a humid environment, causing the concrete to calcify. This process is called the carbonization reaction of the concrete. The main reaction equation is shown in equation (4):

$$
\left\{\begin{array}{c}
\mathrm{Ca}(\mathrm{OH})_{2}+\mathrm{H}_{2} \mathrm{O}+\mathrm{CO}_{2} \rightarrow \mathrm{CaCO}_{3}+2 \mathrm{H}_{2} \mathrm{O} \\
\mathrm{CaO} \cdot 2 \mathrm{SiO}_{2} \cdot 3 \mathrm{H}_{2} \mathrm{O}+\mathrm{CO}_{2} \rightarrow \mathrm{CaCO}_{3} \cdot 2 \mathrm{SiO}_{2} \cdot 3 \mathrm{H}_{2} \mathrm{O}
\end{array}\right.
$$

The carbonization reaction principle of steel fiber concrete is basically the same as that of ordinary concrete.

\section{Numerical example}

Age and compressive strength are the main factors that affect carbonization of steel fiber concrete under unfavorable conditions. Based on the analysis of age factors, taking C50 concrete mixed with steel fiber as an example, carbonation reaction test under different fiber content was carried out.

C50 concrete was mixed with $0 \%, 1 \%, 2 \%$ and $3 \%$ volume ratios of steel fiber to compare the carbonation depth of concrete at $7 \mathrm{~d}, 14 \mathrm{~d}$ and $28 \mathrm{~d}$ ages, and the results were shown in Figure 1.

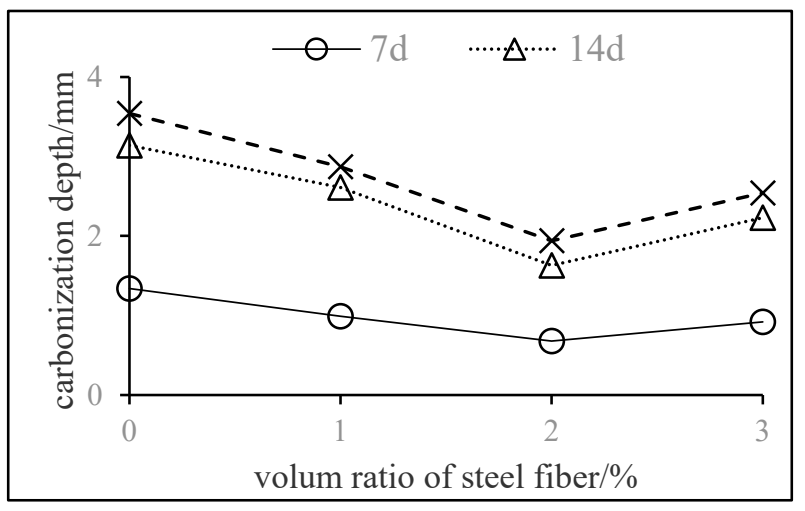

Figure 1 Comparison of carbonization depth of steel fiber concrete at $7 \mathrm{~d} \sim 28 \mathrm{~d}$ age
The results show that the carbonation depth of concrete with different steel fiber content did not show a linear relationship, but had a certain optimal content. As can be seen from Figure 1, when the volume steel fiber content was about $2 \%$, the carbonation depth reached the best. This conclusion indicates that the mathematical model of the carbonization depth of steel fiber concrete cannot be directly applied to the linear model based on the ordinary concrete carbonization depth model [10], but a staged model should be considered. Therefore, based on the above research, the relationship between carbonation depth, steel fiber content and concrete strength was further analyzed.

\subsection{Linear fitting of carbonization depth}

Table 3 shows the linear fitting results of carbonation depth under the classification accuracy of $0 \%, 1 \%, 2 \%$ and $3 \%$ steel fiber volume content for C50 concrete at $0-28 \mathrm{~d}$ age.

Table 3 Linear fitting results of C50 concrete with different steel fiber volume ratio

\begin{tabular}{ccccc}
\hline $\begin{array}{c}\text { Volume } \\
\text { ratio of } \\
\text { steel } \\
\text { fiber/\% }\end{array}$ & $\begin{array}{c}\text { Carbonation } \\
\text { depth equation }\end{array}$ & $\begin{array}{c}\text { Fitness } \\
\mathrm{R} 2 / \%\end{array}$ & $\begin{array}{c}\text { Age } \\
\text { carboniz } \\
\text { ation } \\
\text { coefficie } \\
\mathrm{nt} k_{a}\end{array}$ & $\begin{array}{c}\text { Age } \\
\text { influence } \\
\text { coefficien } \\
\mathrm{t} \eta_{a}\end{array}$ \\
\hline 0 & $Y_{S C}=0.6943 \sqrt{T}$ & 79.65 & & 1 \\
1 & $Y_{S C}=0.5626 \sqrt{T}$ & 75.19 & 0.6943 & 0.8103 \\
3 & $Y_{S C}=0.3706 \sqrt{T}$ & 82.6 & & 0.7118 \\
\hline
\end{tabular}

It can be seen from Table 3 that the linear fitting method could be used to obtain the concrete carbonization depth equation under different steel fiber volume content. The carbonization depth of concrete had a certain correlation with the steel fiber volume ratio, but there was an optimal addition volume. According to this characteristic, the fitting equation of carbonation depth under different volume content of steel fiber was divided into two stages of $0 \% \sim 2 \%$ and $2 \% \sim 3 \%$ :

(1) When the volume ratio of steel fiber was $0 \% \sim 2 \%$,

$Y_{S C}=k_{a} \eta_{a} \sqrt{T}=\left\{\begin{array}{c}0.6943[-0.2331 \phi(\theta)] \sqrt{T} \quad, R^{2}=0.9886 \\ 0.6943\left[-0.0434 \phi^{2}(\theta)-0.1463 \phi(\theta)+1\right] \sqrt{T} \quad, R^{2}=1\end{array}\right.$

(2) When the volume ratio of steel fiber was $2 \% \sim 3 \%$,

$$
Y_{S C}=k_{a} \eta_{a} \sqrt{T}=0.6943[0.178 \phi(\theta)+0.1778] \sqrt{T} \quad, R^{2}=1
$$

\subsection{Polynomial fitting of carbonation depth}

Table 4 shows the polynomial fitting results of the carbonization depth of C50 concrete under the $0 \%, 1 \%$, $2 \%$, and $3 \%$ steel fiber volume content at the $0 \sim 56 \mathrm{~d}$ age. 
Table 4 Polynomial fitting results of C50 concrete with different steel fiber volume ratio

\begin{tabular}{ccccc}
\hline $\begin{array}{c}\text { Volum } \\
\text { e ratio } \\
\text { of steel } \\
\text { fiber/\% }\end{array}$ & $\begin{array}{c}\text { Carbonation depth } \\
\text { equation }\end{array}$ & $\begin{array}{c}\text { Fitne } \\
\text { Ss } \\
\mathrm{R} 2 / \%\end{array}$ & $\begin{array}{c}\text { Age } \\
\text { carboniza } \\
\text { tion } \\
\text { coefficien } \\
\mathrm{t} k_{a 1} / k_{a 2}\end{array}$ & $\begin{array}{c}\text { Age } \\
\text { influence } \\
\text { coefficient } \\
\eta_{a 1} / \eta_{a 2}\end{array}$ \\
\hline 0 & $Y_{S C}=0.00683 T+0.6638 \sqrt{T}$ & 79.74 & & 1 \\
1 & $Y_{S C}=0.01138 T+0.5118 \sqrt{T}$ & 75.5 & & $\begin{array}{c}1.6662 / 0.7 \\
710\end{array}$ \\
& & & $0.00683 / 0$ & $2.0527 / 0.4$ \\
2 & $Y_{S C}=0.01402 T+0.308 \sqrt{T}$ & 83.74 & .6638 & 640 \\
& & & & $1.4934 / 0.6$ \\
3 & $Y_{S C}=0.0102 T+0.4486 \sqrt{T}$ & 80 & & 758 \\
\hline
\end{tabular}

As can be seen from Table 4, the equation of concrete carbonation depth under different steel fiber volume content could also be obtained by polynomial fitting. The carbonation depth of concrete had a certain correlation with the volume ratio of steel fiber, but there was an optimal content. According to this characteristic, the fitting equation of carbonation depth under different volume content of steel fiber was divided into two stages of $0 \% \sim 2 \%$ and $2 \% \sim 3 \%$ :

(1) When the volume ratio of steel fiber was $0 \% \sim 2 \%$,

$$
Y_{S C}=k_{a 1} \eta_{a 1} T+k_{a 2} \eta_{a 2} \sqrt{T}
$$

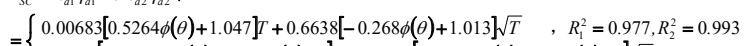

$=\left\{\begin{array}{l}0.0063\left[-0.1398 \phi^{2}(\theta)+0.806 \phi(\theta)+1\right] T+0.6638\left[-0.039 \phi^{2}(\theta)-0.19 \phi(\theta)+1\right] \sqrt{T}, R^{2}=1 \\ 0.0068\end{array}\right.$

(2) When the volume ratio of steel fiber was $2 \% \sim 3 \%$,

$Y_{S C}=k_{a 1} \eta_{a 1} T+k_{a 2} \eta_{a 2} \sqrt{T}$

$=0.00683[-0.5593 \phi(\theta)+3.171] T+0.6638[0.2118 \phi(\theta)+0.0404] \sqrt{T} \quad, \quad R^{2}=1$

\section{Result}

It can be seen from the above calculation examples that both linear fitting and polynomial fitting could get better prediction results. Substitute the above equation and compare with the actual measurement results, as shown in Table 5.

Table 5 Comparison of calculation effectiveness of carbonation depth of C 50 concrete with different steel fiber volume ratio

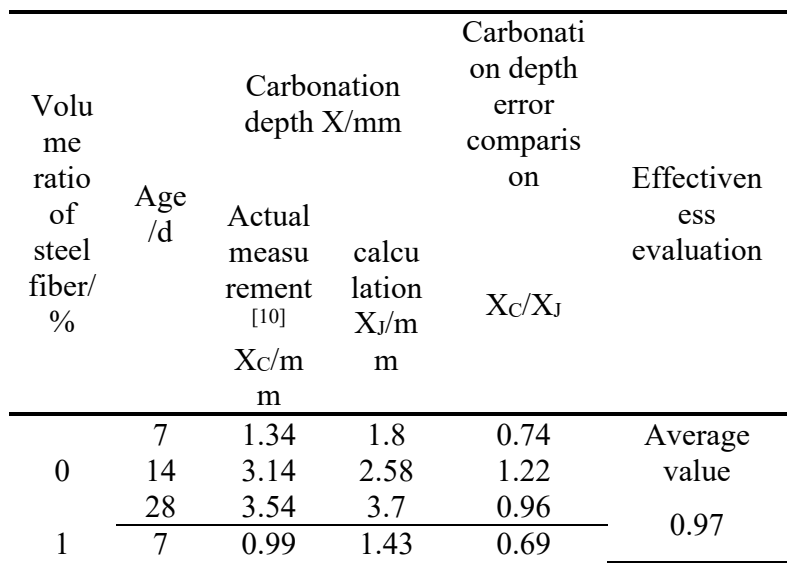

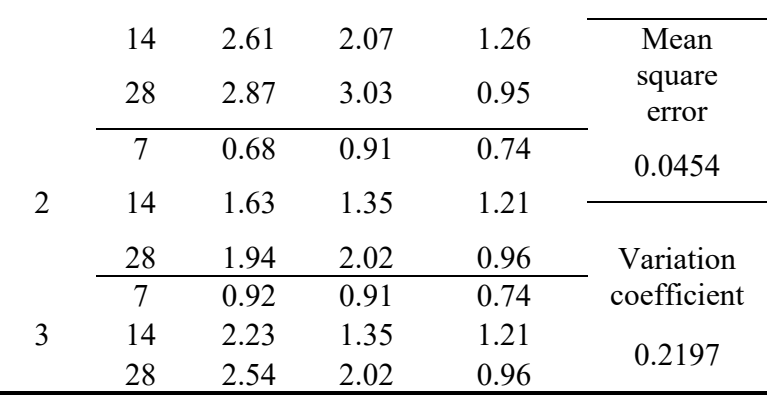

As can be seen from Table 5, although the carbonation depth of steel fiber concrete was different from that of ordinary concrete on the whole, the carbonation depth of both steel fiber concrete and ordinary concrete increased with the growth of age. However, when the volume content of steel fiber was changed, there was an optimal content instead of a linear increasing relationship. Using the method proposed in the present paper to predict the carbonation depth of steel fiber concrete, the average value of the ratio between the measured value and the calculated value was $-3 \%$, the mean square error was 0.0454 , and the coefficient of variation was 0.2197 . The accuracy and reliability of the proposed method were justified.

\section{Conclusion}

The addition of steel fiber can inhibit the carbonization of concrete to some extent, but its quantitative analysis needs to be further studied. In this paper, linear fitting and polynomial fitting methods were adopted to predict the carbonation depth of steel fiber concrete under different fiber volume content, and the following conclusions are drawn.

(1) The carbonation rate of concrete can be reduced by adding steel fiber into concrete;

(2) The mathematical model of the carbonization depth of steel fiber concrete cannot be directly applied to the linear model based on the ordinary concrete carbonization depth model, but a staged model should be considered.

(3) The staged carbonation depth prediction model proposed in this paper has substantial accuracy and reliability.

(4) The addition of steel fiber can inhibit the carbonization of concrete to some extent, but its quantitative analysis needs to be further studied.

\section{Acknowledgments}

This work was partially supported by the Research Project of Jiangxi Provincial Department of Education (GJJ190980).

\section{References}

1. Shen W., Yang D Y., Luo J J., et al. (2017) Research of the long-term mechanical properties of alkali resistant glass fiber concrete. Concrete, 332: 102106.

2. Jin L.,Hang R B., Du XL., et al.(2021)Research 
progress on the influence of temperature on the mechanical performance of concrete structures. China Civil Engineering Journal, 54 (03): 1-18.

3. Zhang K C.(2020)Study on the Durability of Polypropylene-Basalt Fiber Concrete.Non-Metallic Mines.43(05): 45-47+51.

4. Fan X C., Xiong L F., Wang P.(2020)Experimental Study and Theoretical Calculation on Stub Columns Eccentric Compression of BFRP Bars and Hybrid Steel Fiber Reinforced Concrete.Bulletin of the Chinese Ceramic Society,39(10): 3161-3168.

5. Liu R Y., Wang Z J.(2020)Research on crack development of unreinforced steel fiber concrete compression-bending beam. Building Structure, 50 (22): 93-98.

6. Zhang G T.,Zhang M., Zhang L Y.(2020)Prediction of Shear Strength of Fiber Concrete Beams Based on Bayesian Probability Model. Bulletin of the Chinese Ceramic Society,39(03): 770-778.

7. Ning X L.,Wang W P., Hao S., et al.(2020)Effect of Different Fibers on Frost Resistance of Concrete Under Multiple Factors. Industrial Construction, 50(10): 122-128.

8. Zhang W J., Liu B H., Zhou W., et al.(2021) Experimental study on carbonation resistance of rape straw fiber concrete. Journal of Hunan Agricultural University(Natural Sciences), 47(01): 96-100.

9. Wang Z S., Li Y K., Wei J., et al.(2020)Experimental study on corrosion behavior and mechanical properties of basalt fiber concrete by chlorine attack. Journal of Experimental Mechanics, 35(06): 10601070.

10. Wang Z H., Yang D J,(2015)Dynamic Response Analysis of Concrete Rectangular Steel Tube Columns Under Blasting Loading.Journal of Tianjin Chengjian University,21(04):262-266. 